\title{
Therapy effects of gold nanorods on the CNE-I nasopharyngeal carcinoma cell line
}

This article was published in the following Dove Press journal:

Drug Design, Development and Therapy

24 October 2012

Number of times this article has been viewed

\author{
Jinyan Shao' \\ Jianguo Tang' \\ Jian Ji ${ }^{2}$ \\ Wenbo Zhou ${ }^{2}$ \\ 'Department of Otolaryngology, Head \\ and Neck Surgery, Sir Run Run Shaw \\ Hospital, School of Medicine, Zhejiang \\ University, ${ }^{2}$ Department of Polymer \\ Science, Ministry of Education \\ Key Laboratory of Macromolecule \\ Synthesis and Functionalization, \\ Zhejiang University, Hangzhou, \\ People's Republic of China
}

Correspondence: Jianguo Tang

Department of Otolaryngology, Head and Neck Surgery, Sir Run Run Shaw Hospital, School of Medicine, Zhejiang University, Hangzhou 310016,

People's Republic of China

Email tangjg2006@yahoo.com.cn

\begin{abstract}
The use of nanocarriers to deliver drugs to tumor tissue is one of the most important strategies in cancer therapeutics. Recently, gold nanorods (GNRs) have begun to be used in cancer therapy because of their unique properties. The purpose of this study was to show the potential that GNRs have against human nasopharyngeal carcinoma CNE-1 cells, using near-infrared (NIR) laser light. Transmission electron microscopic and ultraviolet-visible spectroscopic investigations confirmed the efficient uptake of the GNRs by CNE-1 and human rhinal epithelia cells. The in vitro NIR photothermal therapy for the CNE-1 and rhinal epithelia cells was designed in three groups: (1) control, (2) laser alone, and (3) GNRs with laser. Fluorescence microscopy images indicated that, at some GNR concentrations and some intensities of NIR laser, GNRs with laser therapy could induce cell death for CNE-1 cells while keeping the rhinal epithelia cells healthy. Therefore, the results of this study suggest that using GNRs with NIR laser therapy can selectively destruct CNE-1 cells while having no effect on normal (rhinal epithelia) cells.
\end{abstract}

Keywords: photothermal therapy, near-infrared laser, rhinal epithelia cells, cell uptake

\section{Introduction}

Nasopharyngeal carcinoma is a squamous cell carcinoma that can occur in the epithelial lining of the nasopharynx, and it is one of the most common head and neck cancers in Southeast Asia and southern China. ${ }^{1}$ Radiotherapy is the standard treatment for nasopharyngeal carcinoma; however, this treatment is not suitable for patients with advanced nasopharyngeal carcinoma. ${ }^{2}$ Recently, investigations have indicated that radiotherapy in combination with chemotherapy is an effective method for nasopharyngeal carcinoma therapy; however, some patients require more effective treatment options or novel therapeutic strategies. ${ }^{3}$ Over the past decade, a significant development in nanotechnology for cancer treatment has been made: nanoscale gold possesses unique size- and shape-dependent properties, a nontoxic nature, stability, and strong light scattering and absorption properties. ${ }^{4}$ Gold nanorods (GNRs), nanoparticles, nanocages, and nanoshells have demonstrated potential as phototherapeutic agents, with each of these indicating strong absorption properties in near-infrared (NIR) laser light due to surface plasmon resonance oscillations. ${ }^{5-7}$ Using pulsed NIR laser light to heat GNRs seems to be a promising strategy for tumor therapy. ${ }^{5,8}$ Pulsed NIR laser light in the presence of GNRs can kill cancerous cells selectively by heating.

Although the use of pulsed NIR laser light in the presence of GNRs to kill some cancerous cells (eg, skin cancer cells, squamous cancer cells) has been investigated, ${ }^{9}$ its use in nasopharyngeal carcinoma therapy and its effects on normal rhinal epithelia cells have not been reported previously. In the present study, uniformly sized GNRs were prepared 
and were stabilized with cetyltrimethylammonium bromide. ${ }^{10,11}$ The GNRs were then administrated to both human nasopharyngeal carcinoma and human rhinal epithelia cells through NIR irradiation and the effect on both cell types was investigated. The purpose of this study was to show the potential that GNRs have against CNE-1 cells, using NIR laser light.

\section{Material and methods Materials}

Human nasopharyngeal carcinoma CNE-1 cells were obtained from Shanghai Institutes for Biological Sciences of Chinese Academy of Sciences (Shanghai, China). Epidermal growth factor, vascular endothelial growth factor, triiodothyronine, vitamin A acid, insulin, MTT [3-(4,5)-dimethylthiahiazo(z-y1)-3,5-di-phenytetrazoliumromide], eosin, and hematoxylin were purchased from Sigma-Aldrich (St Louis, MO). Amphotericin B and hydrocortisone were obtained from Shanghai Pharmaceuticals Holding Co, Ltd (Shanghai, China). Hangzhou Sijiqing Biological Engineering Materials Co, Ltd (Hangzhou, China) provided fetal calf serum. Trypsin, phosphate buffered saline (pH7.4), neutral balsam, and ethanol were purchased from Chinese Medicine Co, Ltd (Shanghai, China). Human anti-keratin antibodies were detected using an enzyme-linked immunosorbent assay kit from Elivision (Fuzhou Maixin Biotechnology Development Co, Ltd, Fuzhou, China). Holmarc Opto-Mechatronics Pvt, Ltd (Kochi, India) provided laser equipment with a power density of 10-500 mW. All biochemicals and chemicals used were of analytical grade. The Ministry of Education Key Laboratory of Macromolecule Synthesis and Functionalization, Zhejiang University, Hangzhou, China, provided GNRs with an optical resonance peak at $780 \mathrm{~nm}$.

\section{Synthesis and characterization of GNRs}

The GNRs were synthesized in cetyltrimethylammonium bromide solution and silver nitrate using a seed-mediated growth method. ${ }^{12}$ The GNRs were characterized through ultraviolet-visible (UV-Vis) spectroscopy and high-resolution transmission electron microscopy. The GNR solution was drop cast onto a carbon-coated copper grid, the solvent was evaporated, and the GNRs were then scanned using a $300 \mathrm{kV}$ transmission electron microscope (Hitachi-800; Hitachi High-Technologies Corporation, Tokyo, Japan).

\section{Primary nasal epithelial establishment and cell culture}

Nasal mucosa samples were taken from patients at Sir Run Run Shaw Hospital, School of Medicine, Zhejiang University, undergoing resection of the inferior turbinate to treat an upper airway obstruction - samples were taken with the permission of the patients. The tissue was rinsed three times in Roswell Park Memorial Institute 1640 medium containing $20 \mathrm{mM}$ of L-glutamine and $50 \mathrm{mg} / \mathrm{mL}$ of gentamicin. The epithelium was detached mechanically from the lamina propria and digested for 18 hours at $4^{\circ} \mathrm{C}$ in trypsin solution $(0.15 \%)$ and ethylenediaminetetraacetic acid (1\%). The suspension was followed by centrifugation at $1500 \mathrm{rpm}$ for 5 minutes to remove the supernatant and obtain the rhinal epithelia cells. The cells were cultured in Dulbecco's Modified Eagle Medium containing fetal calf serum (10\%), insulin (5 mg/L), triiodothyronine $(20 \mathrm{mg} / \mathrm{L})$, hydrocortisone $(0.36 \mathrm{mg} / \mathrm{L})$, vascular endothelial growth factor $(3.75 \mathrm{mg} / \mathrm{L})$, epidermal growth factor $(25 \mathrm{mg} / \mathrm{L})$, vitamin A acid $(100 \mathrm{mg} / \mathrm{L})$, penicillin $(100,000 \mathrm{IU} / \mathrm{L})$, streptomycin $(100 \mathrm{mg} / \mathrm{L})$, and amphotericin B $(2.5 \mathrm{mg} / \mathrm{L})$. The rhinal epithelia cells were then seeded at a density of $4 \times 10^{3}$ on a polystyrene 96 -well cell culture plate. Cultures were maintained at $37^{\circ} \mathrm{C}$ with $5 \%$ carbon dioxide in air, and new media were used after 48 hours. The CNE-1 cells were cultured in the same way as the rhinal epithelia cells. The morphology of the cells was checked qualitatively with a fluorescence microscope (Carl Zeiss AG, Oberkochen Germany), cell viability was determined by fluorescent dye exclusion, and cell proliferation was measured by manual cell counting.

\section{Cellular uptake of GNRs}

In this study, CNE-1 and rhinal epithelia cells were used to investigate the cellular uptake and effects of pulsed laser therapy with GNRs. CNE-1 $\left(4 \times 10^{3}\right)$ and rhinal epithelia cells were incubated with different concentrations of GNRs $\left(5.00 \times 10^{-4}, 2.50 \times 10^{-4}, 1.25 \times 10^{-4}, 6.25 \times 10^{-5}\right.$, $\left.3.13 \times 10^{-5} \mathrm{~mol} / \mathrm{L}\right)$ and at different time intervals $(0,15$, and 30 minutes and 1, 2, 4, 6, 8, 12, and 24 hours). The cells were then viewed under the fluorescent microscope ${ }^{13}$ and the absorption of the GNRs was evaluated using a UV-Vis spectrophotometer (Kejing, Shanghai, China).

\section{In vitro NIR photothermal therapy of CNE-I cells}

As mentioned, the CNE- 1 cells $\left(4 \times 10^{3}\right)$ were incubated with different concentrations of GNRs. Then, a spot about $2 \mathrm{~mm}$ in diameter in each well was exposed to NIR laser light of $780 \mathrm{~nm}$ (diode laser $25.4 \mathrm{~W} / \mathrm{cm}^{2}$ ) and irradiation with different laser power densities $(100,200,300$, and $400 \mathrm{~mW})$ at 30 -second intervals for 2, 3, and 6 minutes. Twenty-four hours after laser irradiation, cells were stained with fluorescent dye 
A

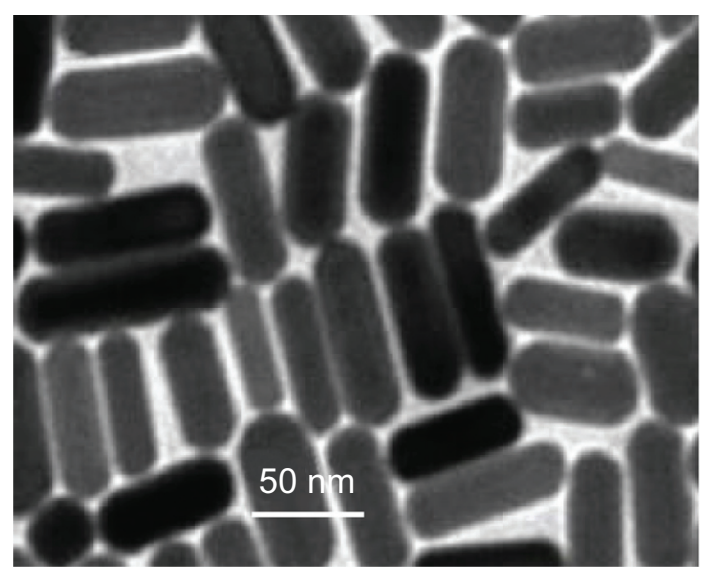

B

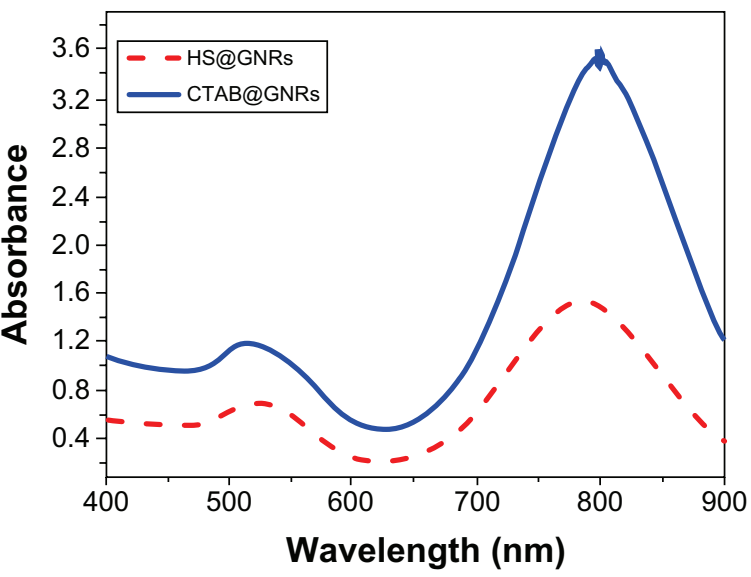

Figure I (A) Transmission electron microscopy image and (B) optical absorption spectra peak of gold nanorods (GNRs).

Abbreviations: HS-@, II-mercaptoundecyl phosphorylcholine coated; CTAB@, cetyltrimethylammonium bromide coated.

to enable determination of the cell viability using the fluorescent microscope. The samples were then observed under a phase contrast microscope (Leica Microsystems, Wetzlar, Germany) at $40 \times$ magnification and the cells were counted.

\section{Statistical analysis}

All statistical analysis was performed with SSPS software (v 10.0; SPSS Inc, Chicago, IL). Unless otherwise specified, the values were expressed as the mean plus or minus the standard deviation.

\section{Results and discussion \\ Preparation, characterization, and cellular uptake of GNRs}

High-resolution transmission electron microscopy images of GNRs (Figure 1A) indicated that the GNRs prepared were monodispersed and were about $50 \mathrm{~nm}$ in length. Optical UV-Vis and NIR absorption spectra indicated that the GNRs had a peak plasmon resonance of $780 \mathrm{~nm}$, with a
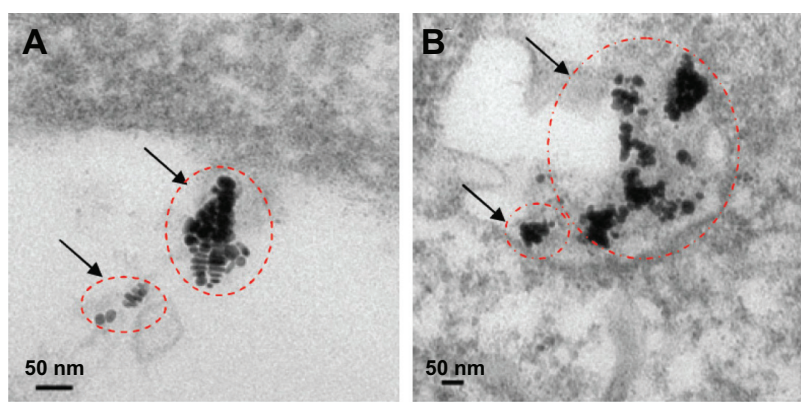

Figure 2 Transmission electron microscopy images of cell uptake of gold nanorods within 5 hours: (A) human rhinal epithelia and (B) human nasopharyngeal carcinoma CNE-I cells. second extinction peak present at $520 \mathrm{~nm}$ due to remaining colloidal gold (Figure 1B). No apparent aggregation or change in the UV-Vis and NIR spectra was observed when the GNRs were stored in phosphate buffered saline at $4^{\circ} \mathrm{C}$ over a period of 4 weeks. The cellular uptake of GNRs over 5 hours was investigated. Figure 2 shows that the GNRs were taken up by rhinal epithelia and CNE-1 cells within 5 hours. Figure 3 shows that the CNE-1 cellular uptake of GNRs was more than the uptake by rhinal epithelia cells after 4 hours.

\section{Effect of GNRs on cellular cytotoxicity}

In order to avoid destroying normal tissue cells of rhinopharyngocele, the authors investigated some normal tissue cells (rhinal epithelia cells, fibroblasts, and human umbilical vein endothelial cells) that had taken up different concentrations of GNRs after 24 hours. Figure 4 shows that the normal tissue cells were not destroyed under the GNR concentration of $3.125 \times 10^{-3} \mathrm{mmol} / \mathrm{L}$. This result suggests efficient

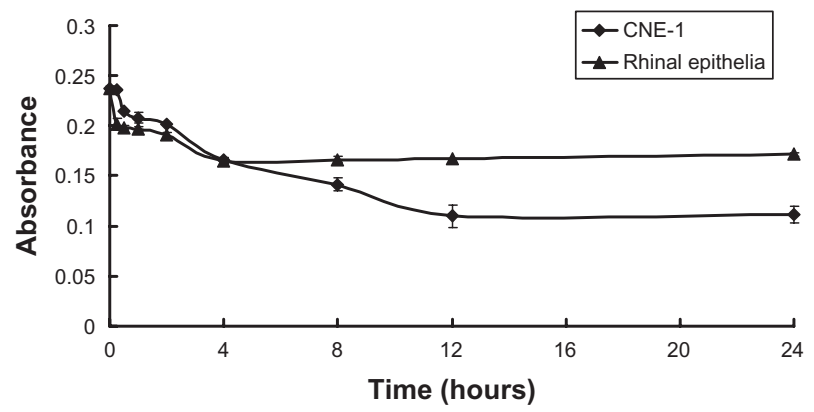

Figure 3 Absorption of gold nanorods (GNRs) detected using a laser in the ultraviolet, visible, and near-infrared spectral range (near-infrared laser power density: $200 \mathrm{~mW}$ ). 


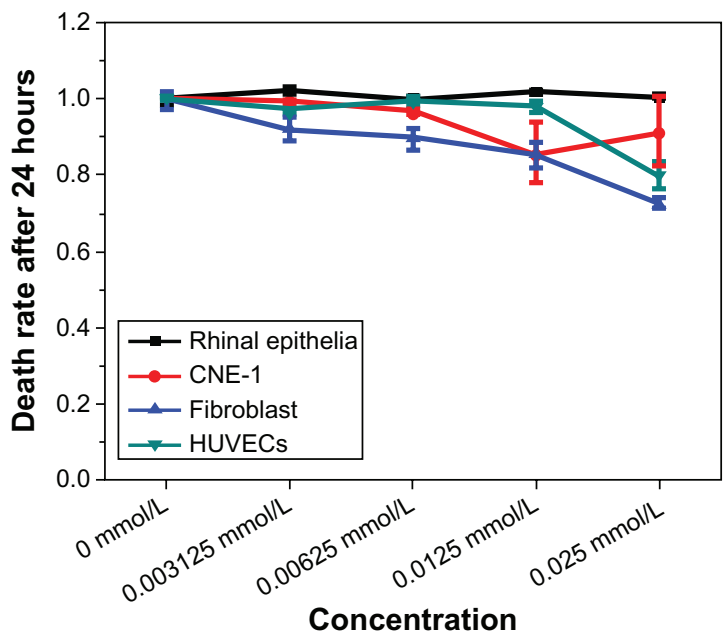

Figure 4 Cytotoxicity of gold nanorods.

Abbreviation: HUVECs, human umbilical vein endothelial cells.

treatment may be achieved under this GNR concentration in NIR photothermal therapy for CNE-1 cells.

\section{Effect of GNRs with NIR therapy on cells}

The authors calculated the safe GNR concentration through the study outlined in the previous paragraph. Following this, the safe NIR laser power density threshold for photothermal therapy was investigated. In order to seek suitable therapy conditions, the authors investigated the effects of GNRs and different intensities of NIR laser on both CNE-1 and normal tissue cells. Both Figure 5 and Table 1 show that different laser power densities achieved different therapy efficacy in CNE-1 cells and did not destroy the normal cells such as rhinal epithelia cells for different times.

CNE-1
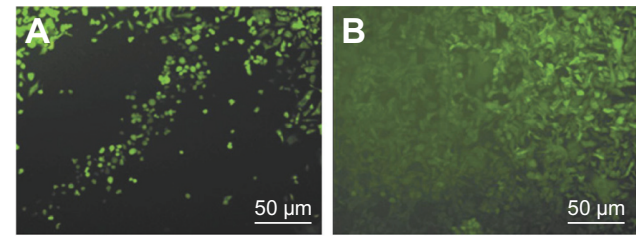

Rhinal epithelia

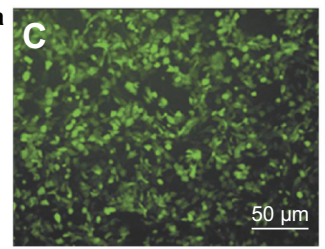

Gold nanorods

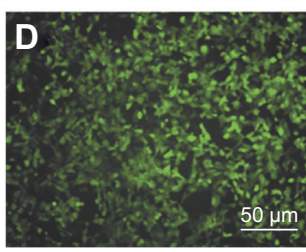

None

Figure 5 Effects of photothermal therapy on different cell types, with cells irradiated with a laser at $200 \mathrm{~mW}$ for 2 minutes: (A) human nasopharyngeal carcinoma CNE-I cells with gold nanorods and laser, (B) human rhinal epithelia cells with gold nanorods and laser, (C) CNE-I cells with laser only, and (D) rhinal epithelia cells with laser only.
Table I The effects of gold nanorods (GNRs) with near-infrared (NIR) laser irradiation on different cell types

\begin{tabular}{llllll}
\hline $\begin{array}{l}\text { NIR laser } \\
\text { power density }\end{array}$ & \multicolumn{2}{l}{$\begin{array}{l}\text { Time to CNE-I } \\
\text { cell death }\end{array}$} & & \multicolumn{2}{l}{$\begin{array}{l}\text { Time to rhinal } \\
\text { epithelia cell death }\end{array}$} \\
\cline { 2 - 3 } \cline { 5 - 6 } $\begin{array}{lllll}\text { GNRs with } \\
\text { laser }\end{array}$ & $\begin{array}{l}\text { Laser } \\
\text { only }\end{array}$ & & $\begin{array}{l}\text { GNR with } \\
\text { laser }\end{array}$ & $\begin{array}{l}\text { Laser } \\
\text { only }\end{array}$ \\
\hline $100 \mathrm{~mW}$ & $5^{\prime} 30^{\prime \prime}$ & $8^{\prime}$ & $6^{\prime}$ & $8^{\prime}$ \\
$200 \mathrm{~mW}$ & $2^{\prime}$ & $2^{\prime} 40^{\prime \prime}$ & $5^{\prime}$ & $2^{\prime} 40^{\prime \prime}$ \\
$300 \mathrm{~mW}$ & $40^{\prime \prime}$ & $I^{\prime} 10^{\prime \prime}$ & $2^{\prime}$ & $2^{\prime}$ \\
$400 \mathrm{~mW}$ & $30^{\prime \prime}$ & $50^{\prime \prime}$ & $I^{\prime}$ & $\mathrm{I}^{\prime}$ \\
\hline
\end{tabular}

Note: GNR concentration, $2.00 \times 10^{-4} \mathrm{~mol} / \mathrm{L}$.

Both Figure 6 and Table 1 show that a $200 \mathrm{~mW}$ NIR laser and a GNR concentration of $2.00 \times 10^{-4} \mathrm{~mol} / \mathrm{L}$ for 2 minutes achieved efficient treatment.

\section{The therapy mechanism of CNE-I cells}

It has long been recognized that primary tumor cells are unusually sensitive to radiation. GNRs with strong light-enhanced absorption in NIR regions and plasmon resonance, thus enhancing their properties to heat, which was an improved class of promising agents for selective therapy against tumors. ${ }^{14,15}$ The NIR laser therapy in the presence of GNRs seemed to induce cancer cell apoptosis and cause selective tumor cell destruction through heating, as the normal tissue cells (rhinal epithelia cells) internalized GNRs less than the CNE-1 cells in 24 hours (Figure 3). When the NIR laser irradiated, the CNE-1 cells had higher light absorption than the normal tissue cells (rhinal epithelia cells) through the mitochondria-dependent pathway (Figures 5 and 6, Table 1). ${ }^{16-20}$ This could possibly have been because the cells uptake of GNRs arrived

CNE-1
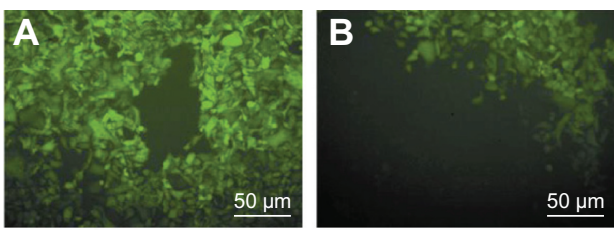

Rhinal epithelia

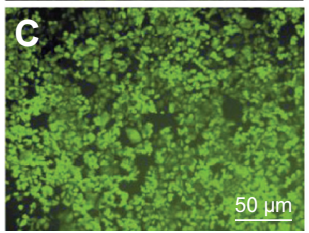

$2 \min$

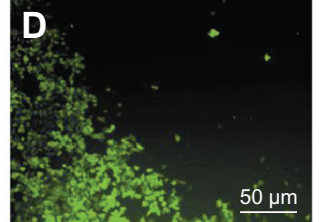

6 min
Figure 6 Effects of gold nanorods and laser $(100 \mathrm{~mW})$ therapy of two different durations on different cell types: human nasopharyngeal carcinoma CNE-I cells irradiated for (A) 2 and (B) 6 minutes, and human rhinal epithelia cells irradiated for (C) 2 and (D) 6 minutes. 
at mitochondria. ${ }^{16}$ These results suggested that the NIR laser in the presence of GNRs could selectively destroy CNE-1 cells while keeping the normal tissue cells (such as rhinal epithelia cells) healthy.

\section{Conclusion}

When NIR laser irradiated, GNRs can be used to kill CNE-1 cells selectively, by apoptosis of CNE-1 cells through the mitochondria-dependent pathway. The results of this study confirm that, by controlling the GNR concentration, the NIR laser energy, and the therapy duration, GNRs can selectively destroy nasopharyngeal carcinoma cells while keeping normal cells, such as rhinal epithelia cells, healthy (as normal). Destruction of the CNE-1 cells was achieved by laser light irradiation and GNRs, while the same method did not affect the rhinal epithelia cells. This study has confirmed that photothermal therapy with pulsed NIR laser light in the presence of GNRs is a potential therapeutic method for the selective destruction of human CNE-1 cells.

\section{Disclosure}

The authors report no conflicts of interest in this work.

\section{References}

1. Wei WI, Sham JS. Nasopharyngeal carcinoma. Lancet. 2005;365(9476): 2041-2054.

2. Lee N, Xia P, Quivey JM, et al. Intensity-modulated radiotherapy in the treatment of nasopharyngeal carcinoma: an update of the UCSF experience. Int J Radiat Oncol Biol Phys. 2002;53(1):12-22.

3. Chan AT, Teo PM, Ngan RK, et al. Concurrent chemotherapy-radiotherapy compared with radiotherapy alone in locoregionally advanced nasopharyngeal carcinoma: progression-free survival analysis of a phase III randomized trial. J Clin Oncol. 2002;20(8):2038-2044.

4. El-Sayed MA. Some interesting properties of metals confined in time and nanometer space of different shapes. Acc Chem Res. 2001;34(4): 257-264.

5. Huang X, El-Sayed IH, Qian W, El-Sayed MA. Cancer cell imaging and photothermal therapy in the near-infrared region by using gold nanorods. J Am Chem Soc. 2006;128(6):2115-2120.
6. Akchurin G, Khlebtsov B, Akchurin G, Tuchin V, Zharov V, Khlebtsov N Gold nanoshell photomodification under a single-nanosecond laser pulse accompanied by color-shifting and bubble formation phenomena. Nanotechnology. 2008;19(1):015701.

7. Ni W, Kou X, Yang Z, Wang J. Tailoring longitudinal surface plasmon wavelengths, scattering and absorption cross sections of gold nanorods. ACS Nano. 2008;2(4):677-686.

8. Petrova H, Perez Juste J, Pastoriza-Santos I, Hartland GV, Liz-Marzán LM, Mulvaney P. On the temperature stability of gold nanorods: comparison between thermal and ultrafast laser-induced heating. Phys Chem Chem Phys. 2006;8(7):814-821.

9. Chou $\mathrm{CH}$, Chen $\mathrm{CD}$, Wang $\mathrm{CR}$. Highly efficient, wavelength-tunable, gold nanoparticle based optothermal nanoconvertors. J Phys Chem B. 2005;109(22):11135-11138.

10. Leonov AP, Zheng J, Clogston JD, Stern ST, Patri AK, Wei A. Detoxification of gold nanorods by treatment with polystyrenesulfonate. ACS Nano. 2008;2(12):2481-2488.

11. Parab HJ, Chen HM, Lai TC, et al. Biosensing, cytotoxicity, and cellular uptake studies of surface-modified gold nanorods. J Phys Chem C. 2009;113(18):7574-7578.

12. Kim F, Song JH, Yang P. Photochemical synthesis of gold nanorods. J Am Chem Soc. 2004;124(48):14316-14317.

13. Pissuwan D, Cortie CH, Valenzuela SM, Cortie MB. Gold nanosphereantibody conjugates for hyperthermal therapeutic applications. Gold Bull. 2007;40(2):121-129.

14. Huang X, Jain PK, El-Sayed IH, El-Sayed MA. Gold nanoparticles: interesting optical properties and recent applications in cancer diagnostics and therapy. Nanomedicine (Lond). 2007;2(5):681-693.

15. Yang DP, Cui DX. Advances and prospects of gold nanorods. Chem Asian J. 2008;3(12):2010-2022.

16. Rejiya CS, Kumar J, Raji V, Vibin M, Abraham A. Laser immunotherapy with gold nanorods causes selective killing of tumour cells. Pharmacol Res. 2012;65(2):261-269.

17. Yang $\mathrm{S}$, Yuan W,Jin T. Formulating protein therapeutics into particulate forms. Expert Opin Drug Deliv. 2009;6(10):1123-1133.

18. Yuan W, Wu F, Geng Y, Xu S, Jin, T. An effective approach to prepare uniform protein-Zn2+ nanoparticles under mild conditions Nanotechnology. 2007;18(14):no.145601.

19. Yuan W, Zhang Y, Wu F, et al. Preparation of protein-loaded sustainedrelease microspheres via 'solid-in-oil-in-hydrophilic oil-in-ethanol (S/O/hO/E)' emulsification. Colloids Surf B Biointerfaces. 2010; 79(2):326-333.

20. Ren T, Yuan W, Zhao H, Jin T. Sustained-release polylactide-co-glycolide microspheres loaded with pre-formulated protein polysaccharide nanoparticles. Micro and Nano Lett. 2011;6(2):70-74.

\section{Publish your work in this journal}

Drug Design, Development and Therapy is an international, peerreviewed open-access journal that spans the spectrum of drug design and development through to clinical applications. Clinical outcomes, patient safety, and programs for the development and effective, safe, and sustained use of medicines are a feature of the journal, which

\section{Dovepress}

has also been accepted for indexing on PubMed Central. The manuscript management system is completely online and includes a very quick and fair peer-review system, which is all easy to use. Visit http://www.dovepress.com/testimonials.php to read real quotes from published authors. 